\title{
KLASIFIKASI CITRA REKAMAN SINYAL ELEKTROKARDIOGRAM MENGGUNAKAN METODE ANALISIS TEKSTUR, K-NN DAN MULTILAYER PERCEPTRON
}

\author{
Mohamad Sofie \\ Program Studi Teknik Elektromedik \\ Akademi Teknik Elektromedik \\ Email: msofie.ms@gmail.com \\ Achmad Rizal \\ Fakultas Teknik Elektro, Program Studi Teknik Elektro \\ Telkom University \\ Email: achmadrizal@telkomuniversity.ac.id
}

\begin{abstract}
ABSTRAK
Sinyal elektrokardiogram (EKG) memiliki informasi yang menggambarkan kondisi kesehatan jantung. Beragai teknik analisis sinyal EKG dikembangkan untuk mengetahui kelainan di jantung secara ototmatis. Pada kenyataannya di Indonesia, kebanyakan perangkat EKG hanya menghasilkan rekaman berupa kertas EKG sehingga metode pengolahan sinyal tidak bisa diterapkan. Pada penelitian ini dilakukan pengenalan kelainan jantung melalui citra rekaman EKG menggunakan analisis tekstur. Garis sinyal EKG yang tergambar dalam citra rekaman EKG diharapkan bisa dibedakan antara kondisi yang satu dengan yang lain. Untuk ekstraksi ciri digunakan ciri statistik orde 1 dan grey level co-occurence matrix (GLCM) pada arah $0^{\circ}, 45^{\circ}, 90^{\circ}$, dan $135^{\circ}$. Untuk klasifikasi digunakan K-nearest neighbor (K-NN) dan multilayer perceptron (MLP). Akurasi yang dihasilkan mencapai $44.12 \%$ untuk lima kelas data dan $65.82 \%$ untuk dua kelas data. Penggunaan teknik pengolahan ctra terbukti mampu meningkatkan akurasi yang semula rendah.
\end{abstract}

Kata kunci: analisis tekstur, $K-N N$, multilayerperceptron, citra rekaman EKG, pengolahan citra.

\begin{abstract}
Electrocardiogram (ECG) signal has information that describes the condition of heart health. Various ECG signals analysis techniques was developed to determine abnormalities in the heart automatically. In fact in Indonesia, most devices only generate ECG recordings in the form of paper so that the ECG signal processing methods can not be applied. In this research, we use texture analysis to determine cardiac abnormalities through ECG recording images. ECG signal line depicted in the image of the ECG recording is expected to distinguish one condition from one another. Feature extraction methods used are statistics order 1 and gray level co-occurrence matrix (GLCM) in the direction of 0, 45, 90 and 135 degrees. For classification step, we used for K-nearest neighbor $(k-N N)$ and multilayer perceptron (MLP). The resulting accuracy reaches $44.12 \%$ for the five classes of data and $65.82 \%$ for the two categories of data. The use of image processing techniques is proven to increase the accuracy.
\end{abstract}

Keywords: texture anaysis, K-NN, multilayer perceptron, ECG recording image, image processing.

\section{PENDAHULUAN}

Kematian yang disebabkan oleh penyakit kardiovaskuler, terutama penyakit jantung koroner dan stroke diperkirakan akan terus meningkat mencapai 23,3 juta kematian pada tahun 2030. Selain itu prevalensi penyakit jantung koroner dan gagal jantung terlihat meningkat seiring peningkatan umur responden. Penyakit jantung iskemik mempunyai prevalensi sebesar $7.2 \%$ secara nasional dengan penyebab kematian akibat penyakit kardiovaskuler menempati 6-12\% di rumah sakit [1].

Salah satu informasi yang mengungkap tingkat kesehatan jantung adalah sinyal elektrokardiogram (EKG). Sinyal EKG dihasilkan dari aktifitas kelistrikan jantung [2]. Sinyal EKG diukur menggunakan perangkat elektrokardiograf untuk kemudian ditampilkan, dicetak, dan dan dinterpretasi oleh dokter [2].

Berbagai teknik dikembangkan peneliti agar dapat mengenali kelainan jantung melalui sinyal EKG secara otomatis. Pengolahan sinyal EKG pada domain waktu dilakukan pada [3]-[5]. Metode yang digunakan diantaranya principal component analysis (PCA) dan Hjorth descriptor [6]. Teknik lain 
misalnya menggunakan wavelet [7], analisis frekuensi [8] atau analisis kompleksitas menggunakan entropi [9].

Teknik-teknik pengolahan sinyal tersebut diterapkan pada sinyal EKG hasil rekaman perangkat elektrikardiograf. Pada kenyataannya, kebanyakan perangkat elektrokardiograf di rumah sakit di Indonesia menghasilkan rekaman sinyal EKG berupa citra. Oleh karena itu teknik-teknik pengolahan sinyal yang diusulkan tidak bisa diterapkan secara langsung.

Pada penelitian ini dilakukan pengenalan jenis kelainan EKG menggunakan citra rekaman EKG sebagai data masukan. Citra rekaman EKG dipindai kemudian dilakukan ekstraksi ciri menggunakan metode analisis teksture. Diharapkan garis yang terbentuk dari rekaman sinyal EKG dapat dibedakan menggunakan metode ini. Pada penelitian sebelumnya dilakukan penelitian yang sama menggunakan metode wavelet dengan data yang berbeda [10]. Hasil akurasi terbaik mencapai $85 \%$ untuk dua kelas yang berbeda. Pada penelitian ini penelitian dilakukan pada lima kelas yang berbeda. Diharapkan metode yang diusulkan memberikan hasil yang lebih baik.

\section{METODOLOGI PENELITIAN}

Metode yang digunakan dalam dalam penelitian ini seperti di ilustrasikan pada Gambar 1. Lebih detail dari metode yang dilakukan dijelaskan pada subbab selanjutnya.

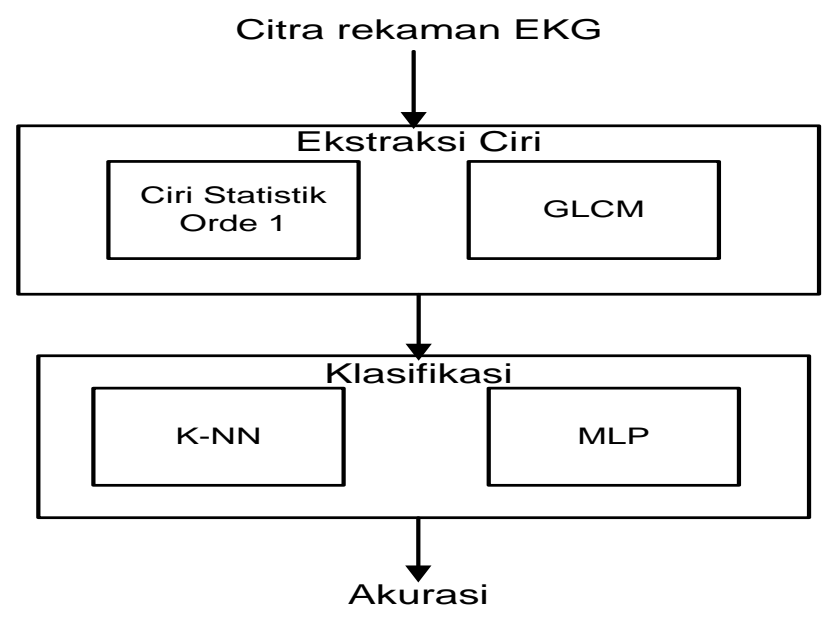

Gambar 1. Metode yang dilakukan

\subsection{Data Citra Rekaman EKG}

Data masukan berupa citra rekaman EKG dikumpulkan dari RSUD Tugu, Semarang. Kelainan pada rekaman EKG berupa Atrium Fibrillation (AF), Infrak Miokard Akut (AMI), Ischemia, Left Bundle Brunch Block (LBBB) dan Normal (N) yang di scan dengan menggunakan scan printer merk HP 1050. Data citra rekaman dari pasien sebelumnya di-croping dengan ukuran 4x12 kotak besar pada kertas EKG.

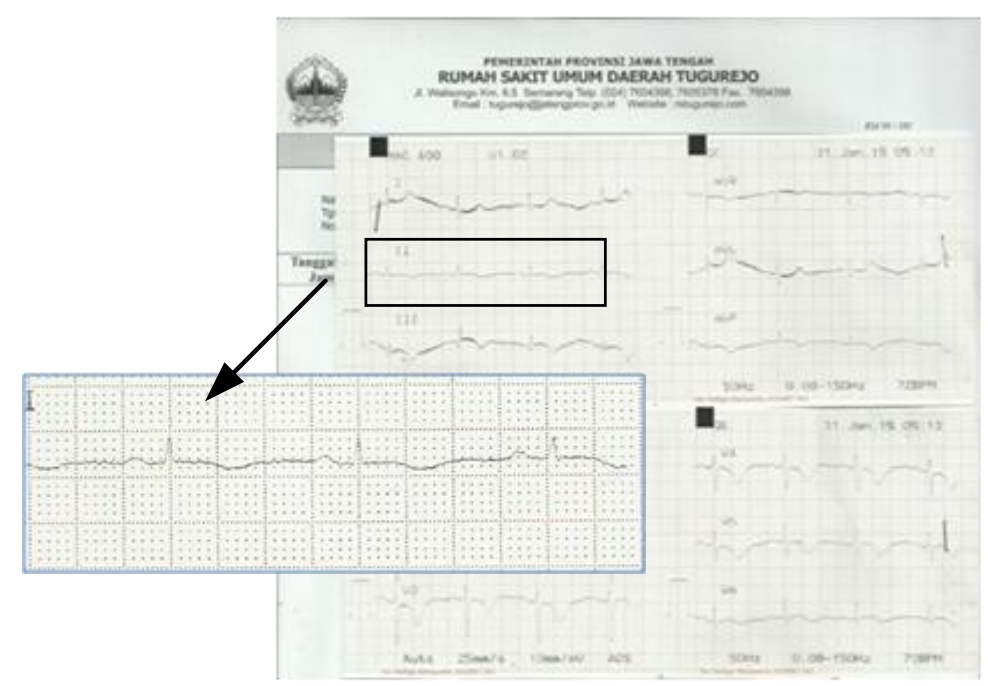

Gambar 2. Data citra rekaman EKG di-cropping 
Tabel 1. Data Citra EKG

\begin{tabular}{lc}
\hline \multicolumn{1}{c}{ Kelas Data } & Jumlah data \\
\hline AF & 22 \\
AMI & 11 \\
Ischemi & 19 \\
LBBB & 10 \\
Normal & 6 \\
\hline
\end{tabular}

\subsection{Preprocessing dan Ekstraksi Ciri}

Preprocessing yang dilakukan hanya mengubah citra dari RGB ke grayscale untuk memudahkan proses selanjutnya. Sementara itu ektraksi ciri yang dilakukan adalah penguruan ciri statistik orde 1 dan grey level cooccurance matrix (GLCM) [11]. Ciri statistik orde 1 yang digunakan adalah [12]:

a. Mean $(\mu)$

$\mu=\sum_{n=0}^{255} I_{n} \cdot p\left(I_{n}\right)$

Mean menyatakan penyebaran nilai intensitas dalam citra. Citra dengan nilai mean yang tinggi menunjukkan citra dengan tingkat kecerahan tinggi. Citra yang cenderung gelap mempunyai nilai mean yang rendah.

b. Variance $\left(\sigma^{2}\right)$

$$
\sigma^{2}=\sum_{i=0}^{255}(i-\mu)^{2} \mathrm{p}(\mathrm{i})
$$

Nilai variansi menyatakan variasi elemen dalam histogram citra. Variansi yang tinggi dicapai oleh citra dengan kontas tinggi sedangkan citra dengan kontras rendah mempunyai nilai variansi yang rendah.

c. Skewness $\left(\alpha_{3}\right)$

$\alpha_{a}=\frac{1}{\sigma^{3}} \sum_{i=0}^{255}(i-\mu)^{a} p(i)$

Skewness merupakan ukuran kesimetrian histogram dari citra. Dengan kata lain skewness menunjukkan kemencengan relatif histogram suatu citra. Citra yang cenderung gelap mempunyai histogram yang mempunyai puncak cenderung ke nilai rendah sedangkan citra yang terang mempunyai histogram yang cenderungke arah kanan (nilai tinggi).

d. Kurtosis $\left(\alpha_{4}\right)$

$\alpha_{4}=\frac{1}{\sigma^{4}} \sum_{i=0}^{255}(i-\mu)^{4} p(i)-3$

Kurtosis menunjukan kemiripan histogram terhadap distribusi normal. Distribusi intensitas citra yang terlihat dalam histogram terlihat meruncing di titik tengah atau mendatar.

e. Entropi (H)

$$
H=-\sum n p\left(I_{n}\right) \cdot \log _{2} \times p\left(I_{n}\right)
$$

Dalam teori informasi entropi dinyatakan sebagai ukuran jumlah informasi dalam suatu pernyataan atau variable. Dalam ekstraksi ciri dari suatu citra, entropi menyatakan ketidakaturan suatu citra.

Sementara itu ciri GLCM yang digunakan adalah [11]:

a. Angular Second Moment, ukuran sifat homogenitas citra.

$$
A S M=\Sigma_{i} \sum_{j}\{p(i, j)\}^{2}
$$

b. Contrast, ukuran penyebaran (momen inersia) elemen-elemen matriks citra.

$$
\operatorname{CON}=\sum_{i} \sum_{j}|i-j|^{2} \cdot p\left(i_{i} j\right), i-j=k
$$

c. Correlation, ukuran ketergantungan linear derajat keabuan citra

$$
\operatorname{COR}=\Sigma_{i} \Sigma_{j} \frac{\left(i-\mu_{j}\right) p\left(\mathrm{i}_{i} j\right)}{\sigma_{i} \sigma_{j}}
$$


d. Variance variasi elemen-elemen matriks kookurensi.

$V A R=\Sigma_{i} \Sigma_{j}\left(i-\mu_{i}\right)\left(j-\mu_{j}\right) \cdot p\left(i_{s} j\right)$

e. Inverse Different Moment, ukuran kehomogenan citra yang berderajat keabuan sejenis.

$I D M=\Sigma_{i} \Sigma_{j} \frac{p(i j)}{1+\mid i-j]}$

f. Entropy, ukuran ketidakteraturan bentuk.

$E N T_{2}=-\Sigma_{i} \Sigma_{j} p\left(i_{v} j\right) \cdot \log _{2} \cdot p\left(i_{v} j\right)$

Ciri GLCM dihitung pada arah $0^{\circ}, 45^{\circ}, 90^{\circ}$, dan $135^{\circ}$ sehingga total akan diperoleh 29 ciri.

\section{$2.3 \quad$ Klasifikasi}

Untuk proses klasifikasi digunakan K-nearest neighbor (K--NN) dan multilayer perceptron (MLP). Untuk K-NN digunakan $\mathrm{K}=1$, 3, dan 5. Klasifikasi menggunakan MLP dilakukan menggunakan tiga nilai hidden neuron yang berbeda yaitu 15, 30 dan 45 seperti dalam [13]. Mengingat jumlah data yang sedikit maka pembagian data latih dan data uji adalah 50\%-50\%.

\section{HASIL DAN PEMBAHASAN}

\subsection{Hasil Klasifikasi Menggunakan Ciri Statistik Orde 1 dan GLCM}

Pada tahap ini ekstraksi ciri dilakukan tanpa melakukan pengolahan citra pada citra input. Citra dibaca kemudian diekstraksi ciri dan selanjutnya dilakukan klasifikasi. Untuk ciri statistik orde 1, diuji sendiri dan dicoba digabung dengan ciri GLCM. Sementara itu ciri GLCM diuji pada satu arah, keseluruhan arah dan digabung dengan ciri statistik orde 1. Hasil dari tiap pengujian menggunakan K-NN dan MLP seperti pada Gambar 3 dan Gambar 4.

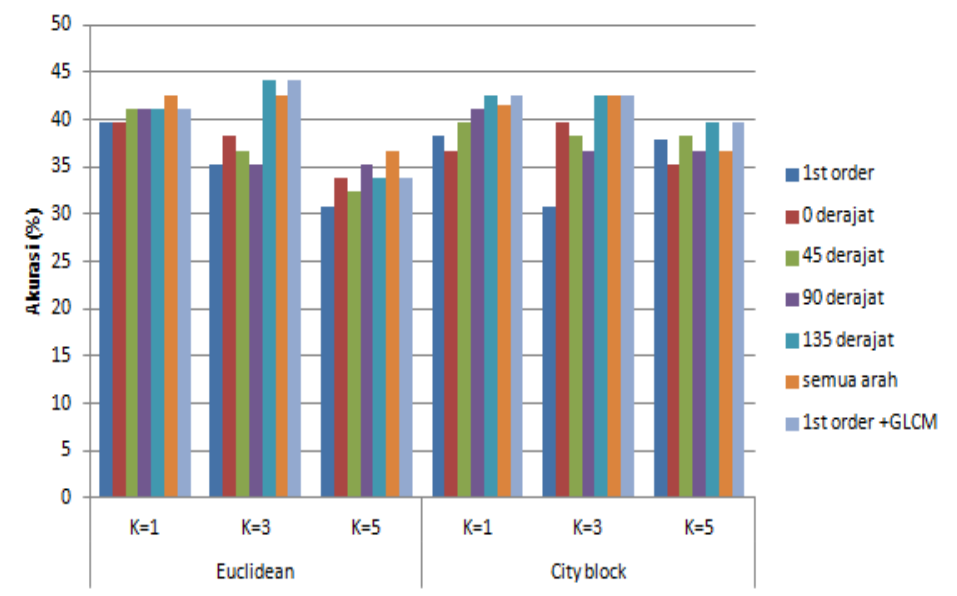

Gambar 3. Akurasi untuk ekstraksi ciri statistik orde 1 dan GLCM menggunakan K-NN, akurasi tertinggi $44.12 \%$ untuk GLCM arah $135^{\circ}$ dan semua fitur, jarak Euclidean $K=3$



Gambar 4. Akurasi untuk ekstraksi ciri statistik orde 1 dan GLCM menggunakan MLP, akurasi tertinggi 39.71\% untuk ciri GLCM semua arah dan MLP N-45-5 
Akurasi tertinggi didapat pada ciri gabungan GLCM dan ciri statistik orde 1 menggunakan K-NN. Akurasi tertinggi 44,12\%. Nilai ini cukup rendah disebabkan data yang mempunyai resolusi cukup rendah dengan noise yang cukup banyak. Beberapa data tidak menunjukkan bentuk yang berbeda antar kelas dan beberapa data menunjukkan perbedaan yang cukup tinggi interkelas. Pengolahan citra diperlukan untuk pengujian berikutnya.

\subsection{Hasil Klasifikasi dengan Dua Kelas Data}

Salah satu permasalahan utama dalam penelitian ini adalah jumlah data yang tidak seimbang, seperti pada Tabel 1. Untuk itu pada bagian ini dicoba untuk melakukan klasifikasi untuk 2 kelas data yang mempunyai jumlah data yang relative banyak dan seimbang. Untuk itu data AF dan Ischemia digunakan pada pengujian ini. Pengujian menggunakan K-NN dan MLP dengan 3-fold cross validation [14]. Hasil yang di dapat seperti pada Gambar 5 dan Gambar 6.

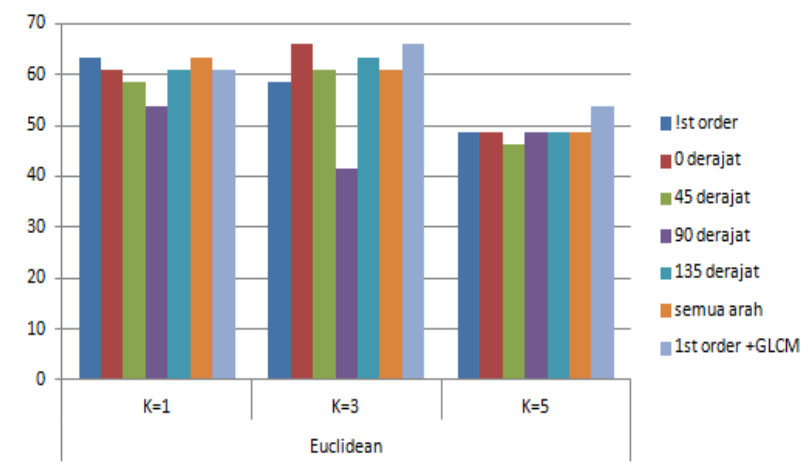

\section{Gambar 5. Akurasi menggunakan ciri GLCM dan ciri statistic orde 1 dan K-NN untuk AF dan Ischemia}

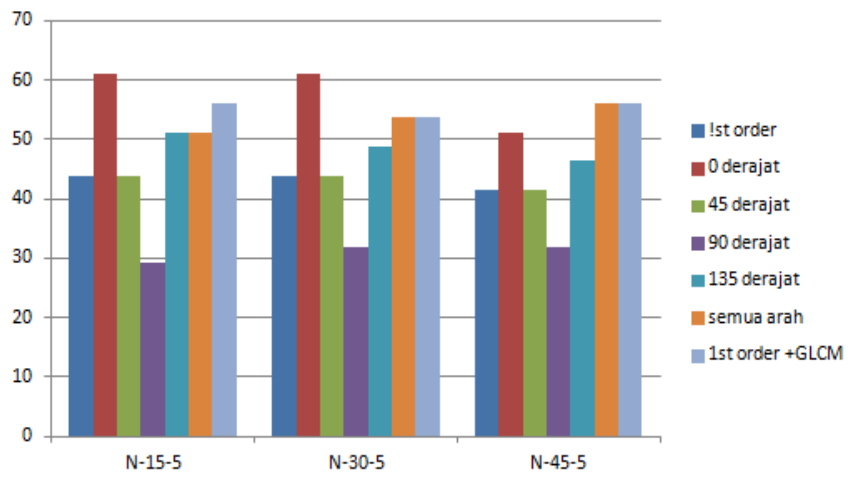

\section{Gambar 6. Akurasi menggunakan ciri GLCM dan ciri statistic orde 1 dan MLP untuk AF dan Ischemia}

Gambar 5 menunjukkan akurasi tertinggi $65.85 \%$, untuk arah $0^{\circ}$ dan seluruh ciri, lebih baik dari hasil pada Gambar 3. Sementara itu klasifikasi menggunakan MLP menghasilkan akurasi tertinggi $60.97 \%$, untuk GLCM arah $0^{\circ}$ meningkat dari hasil pada Gambar 4. Hasil yang didapat untuk klasifikasi 2 kelas menunjukkan peningkatan akurasi menjadi di atas $60 \%$. Hasil ini dipengaruhi oleh jumlah data yang relatif seimbang.

\subsection{Pembahasan}

Seperti yang telah disajikan pada Gambar 3-6, akurasi tertinggi hanya mencapai $65.85 \%$ untuk klasifikasi menggunakan 2 kelas yaitu AF dan Ischemia. Permasalahan utama pada penelitian ini adalah jumlah data yang tidak seimbang dan kualitas data yang relatif rendah. Beberapa distrosi yang terjadi disebabkan oleh sumber citra rekaman EKG yang berbeda, proses cropping yang mungkin tidak seragam dan pola sinyal EKG yang terekam hampir sama antara pola yang satu dengan yang lain. Sebagai contoh Gambar 7 menampilkan sinyal EKG untuk kasus AF, Normal dan AMI. Ketiga citra rekaman jantung hampir mirip yaitu terdapat fibrilasi pada baseline. Perbedaannya pada AF tidak terlihat gelombang P, Q, $\mathrm{S}$, dan T sedangkan pada Normal ada. 


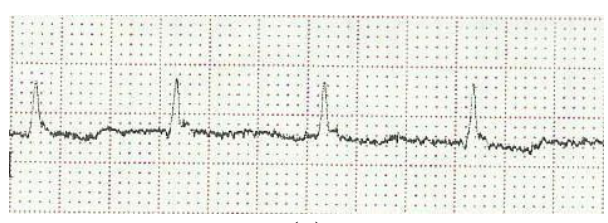

(a)

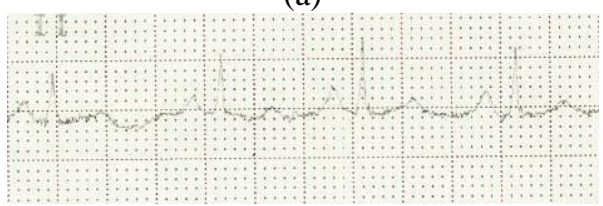

(b)

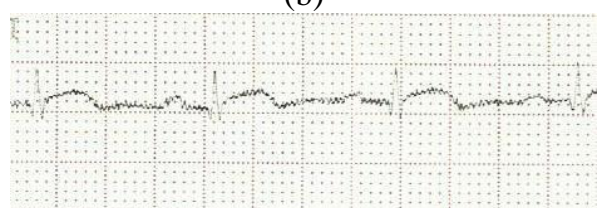

(c)

Gambar 7. a. Citra rekaman AF. b. Citra rekaman Normal. C. Citra rekaman AMI

Pada Gambar 7 juga terlihat bahwa garis sinyal EKG terlihat sangat tipis sehingga membutuhkan proses perbaikan citra untuk lebih menonjolkan sinyal EKG pada citra. Beberapa proses pengolahan citra yang bisa dilakukan untuk meningkatkan kulaitas citra masukan misalnya histogram equalization (HE), contrast limited adaptive histogram equalization (CLAHE) dan operasi morfologi lainnya [15]. Gambar 8 menampilkan hasil beberapa proses pengolahan citra pada citra rekaman EKG.

Untuk menguji peningkatan akurasi setelah proses pengolahan citra, maka dilakukan HE pada citra rekaman EKG. Ciri yang digunakan adalah ciri GLCM untuk semua arah dan gabungannya dengan ciri statistik orde 1. Hasil yang didapat seperti pada Gambar 9 dan Gambar 10.
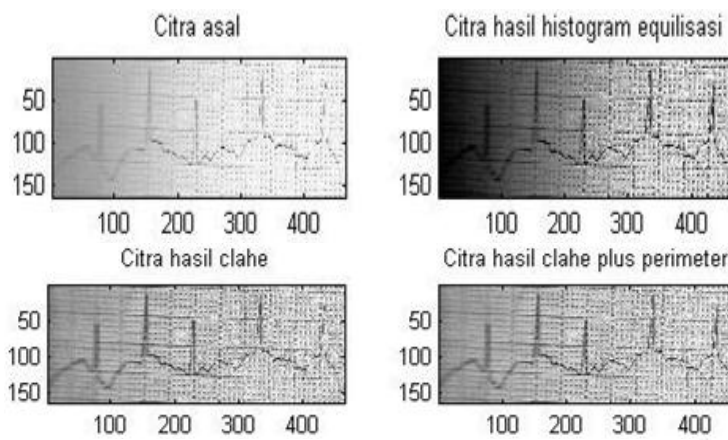

Citra hasil clahe plus perimeter
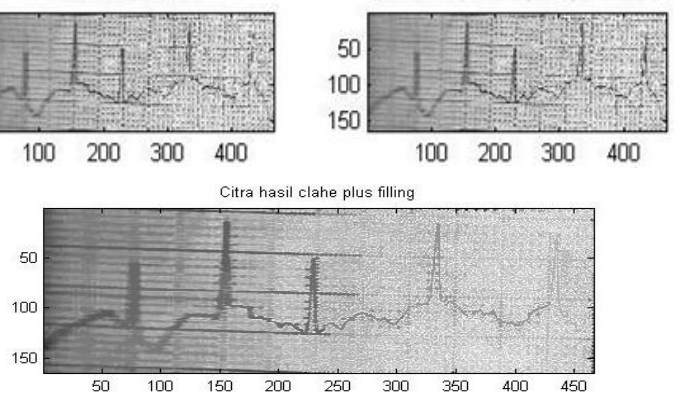

Gambar 8. Hasil beberapa pengolahan citra berbasis HE

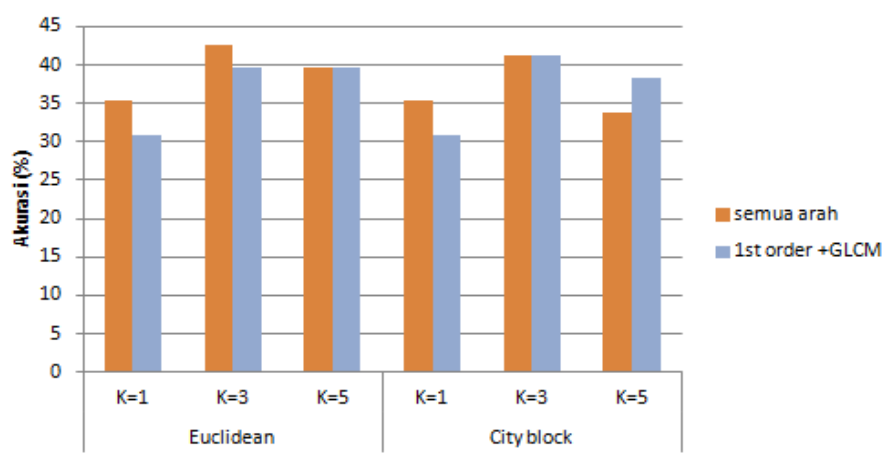

Gambar 9. Akurasi setelah citra dilakukan proses HE, akurasi tertinggi $42.65 \%$ untuk ciri GLCM, $\mathrm{K}-\mathrm{NN}, \mathrm{K}=3$ dan jarak eulidean 


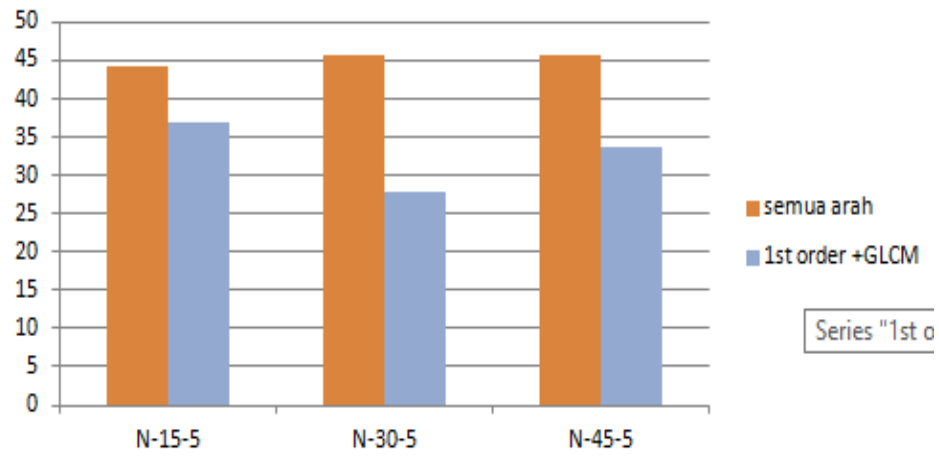

\section{Gambar 10 Akurasi setelah citra dilakukan proses HE, akurasi tertinggi $45.59 \%$ untuk ciri GLCM, MLP}

Hasil yang didapat sedikit meningkat dibandingkan dengan hasil yang ditunjukkan pada Gambar 3 dan Gambar 4. Sekalipun peningkatan akurasi tidak terlalu signifikan, hal ini mengisyaratkan bahwa pemilihan teknik pengolahan citra yang tepat akan dapat meningkatkan akurasi system. Ke depan perlu dicari metode yang tepat untuk kasus ini.

Dibandingkan dengan penelitian sebelumnya, hasil yang didapat secara umum lebih buruk [10]. Kelebihan dari penelitian ini adalah jumlah kelas data yang relatif banyak dan proses pengambilan data yang lebih standar. Beberapa hal yang bisa dilakukan untuk meningkatkan akurasi sistem antara lain:

a. seleksi data, beberapa data dari kelas yang sama memperlihatkan perbedaan yang signifikan karena adanya noise dan baseline yang tidak stabil

b. pre-processing untuk perbaikan kualitas citra, beberapa metode sedang diujicoba misalnya filter median, Clahe, dan operasi morfologi.

c. perbaikan data masukan, resolusi data masukan sangat kecil sehingga beberapa operasi pengolahan citra tidak bisa diaplikasikan.

d. data citra rekaman EKG yang normal kurang bagus, dikarenakan garis pembentuk sinyal jantung tidak mulus atau seperti terjadi fibrilasi. Meskipun interpretasi pada alat menyatakan Normal. Hal ini dimungkinkan karena grounding EKG saat digunakan kurang baik.

\section{KESIMPULAN}

Pada penelitian ini telah dilakukan ekstraksi ciri citra rekaman EKG menggunakan ciri statistik orde 1 dan GLCM. Hasil yang didapat belum memuaskan karena jumlah data yang tidak seimbang, dan kualitas data yang kurang baik. Diperlukan pengolahan citra untuk meningkatan kualitas citra masukan sehingga akurasi system bisa meningkat. Penelitian ini berguna untuk mengatasi permasalahan perangkat EKG di rumah saikt yang biasanya hanya menghasilkan rekaman berupa kertas EKG yang diinterpretasi secara manual.

Untuk meningkatkan performansi system, perlu diuji beberapa teknik pengolahan citra digital untuk meningkatkan kualitas citra masukan. Metode lain yang mungkin bisa dilakukan adalah mengkonversi titik-titik dari sinyal menjadi sinyal berupa data sample sehingga pengolahan yang dilakukan tidak lagi menggunakan pengolahan citra tetapi menggunakan pengolahan sinyal. Dengan demikian komputasi akan lebih ringan.

\section{DAFTAR PUSTAKA}

[1] Kesehatan, Kementrian, (2016) "Penanganan penyakit jantung harus sesuai ilmu kedokteran terkini dan mengutamakan keselamatan pasien," [Online]. Available: http://www.depkes.go.id/article/view/14112700011/penanganan-penyakit-jantung-harus-sesuaiilmu-kedokteran-terkini-dan-mengutamakan-keselamatan-pasien.html. [Accessed: 01-Feb-2016].

[2] Tompkins, W. J. (2000), "Electrocardiography," in Biomedical Digital Signal Processing, W. J. Tompkins, Ed. New Jersey: Prentice Hall, 2000, pp. 24-54.

[3] Xiao, Q. U., C. Wei, and G. D. Fei, 2011. "ECG Signal Classification Based on BPNN," in Electric Information and Control Engineering (ICEICE), 2011 International Conference on, no. 1, pp. 1362 -1364 .

[4] Bollmann, A. et. Al. 2007. "Principal Component Analysis in ECG Signal Processing," EURASIP J. Adv. Signal Process., vol. 2007

[5] Nait-hamoud, N., A. Moussaoui, 2010. "Two Novel Methods for Multiclass ECG Arrhythmias Classification Based on PCA , Fuzzy Support Vector Machine and Unbalanced Clustering," in 
International Conference on Machine and Web Intelligence (ICMWI), pp. 140-145.

[6] Rizal, A., S. Hadiyoso, 2015. "ECG Signal Classification Using Hjorth Descriptor," in 2015 International Conference on Automation, Cognitive Science, Optics, Micro Electro-Mechanical System, and Information Technology (ICACOMIT), no. 2, pp. 3-6.

[7] Rizal, A., V. Suryani, 2008. "Pengenalan Signal EKG Menggunakan Dekomposisi Paket Wavelet dan K-Means Clustering," in Proceeding Seminar Nasional Aplikasi Teknologi Informasi 2008(SNATI 2008), 5-8.

[8] Lin, C., 2008. "Frequency-domain features for ECG beat discrimination using grey relational analysis-based classifier," Comput. Math. with Appl., vol. 55, no. 4, pp. 680-690

[9] Wu, H., et. al, 2013. "Multiscale Cross-Approximate Entropy Analysis as a Measurement of Complexity between ECG R-R Interval and PPG Pulse Amplitude Series among the Normal and Diabetic Subjects," Comput. Math. Methods Med., vol. 2013, 2013.

[10] Sofie, M., et. al, 2015. "Pengenalan Citra Rekaman ECG Atrial Fibrilation dan Normal Menggunakan Dekomposisi Wavelet dan K-Mean Clustering," in Seminar Nasional Sains dan Teknologi ke-6.

[11] Haralick, R., K. Shanmugan, and I. Dinstein, 1973. "Textural features for image classification," IEEE Trans. Syst. Man Cybern., vol. 3, pp. 610-621.

[12] Goshtasby, A., (2012) Image Registration, Priciples, Tools and Methods, First. Springer-Verlag London Limited.

[13] Hashemi, A., H. Arabalibiek, K. Agin, 2011. "Classification of Wheeze Sounds Using Wavelets and Neural Networks," in International Conference on Biomedical Engineering and Technology (2011), vol. 11, pp. 127-131.

[14] Palaniappan, R., (2010) Biological Signal Analysis. Ventus Publishing ApS.

[15] Putri, F. K. , D. Saepudin, A. Rizal, (2014) "Analisis Contras Limited Adaptive Histogram Equalization (CLAHE) dan Region Growing dalam Deteksi Gejala Kanker Payudara pada Citra Mammogram," Elektro, vol. 7, no. 1, pp. 15-28 